CONF- $9505-87-.5$

\title{
BIOCHEMICAL PROCESSING OF HEAVY OILS AND RESIDUUM
}

Mow S. Lin, Eugene T. Premuzic, Jeffrey H. Yablon, and Wei-Min Zhou

\author{
Biosystems and Process Sciences Division \\ Department of Applied Science \\ Brookhaven National Laboratory \\ Upton, NY 11973
}

May 1995

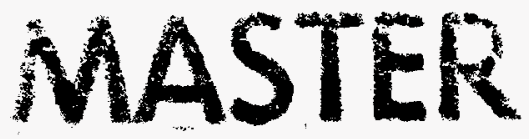

Presented at the Seventeenth Symposium on

Biotechnology for Fuels and Chemicals

Vail, Colorado
May 7-11, 1995

Also published in the J. of Applied Biochemistry and Biotechnology,

Vol. 57/58, 659-664 (1996).

DBOTRSUTON OF THIS DOCUMENT IS UAMTED /C

Under Contract No. DE-AC02-76CH00016 with the U.S. Department of Energy. 


\section{DISCLAIMER}

This report was prepared as an account of work sponsored by an agency of the United States Government. Neither the United States Government nor any agency thereof, nor any of their employees, make any warranty, express or implied, or assumes any legal liability or responsibility for the accuracy, completeness, or usefulness of any information, apparatus, product, or process disclosed, or represents that its use would not infringe privately owned rights. Reference herein to any specific commercial product, process, or service by trade name, trademark, manufacturer, or otherwise does not necessarily constitute or imply its endorsement, recommendation, or favoring by the United States Government or any agency thereof. The views and opinions of authors expressed herein do not necessarily state or reflect those of the United States Government or any agency thereof. 


\section{DISCLAMMER}

Portions of this document may be illegible in electronic image products. Images are produced from the best available original document. 


\title{
Biochemical Processing of Heavy Oils and Residuum
}

\author{
Mow S. Lin, Eugene T. Premuzic \\ Jeffrey H. Yablon, and Wei-Min Zhou \\ Brookhaven National Laboratory, \\ Department of Applied Science, \\ Biosystems and Process Sciences Division, \\ Upton, New York 11973
}

Index Entries: Biotechnology; petroleum; sulfur; nitrogen; metal

\section{INTRODUCTION}

During the past several decades, the petroleum industry has adjusted gradually to accommodate the changes in market product demands, government regulations, and the quality and cost of feedstock crude oils. For example, the trends show that the demand for distillate fuels, such as diesel, as compared to gasoline are increasing. Air-quality standards have put additional demand on the processing of heavier and higher sulfur feed stocks. Thus, the 1990 Clean Air Act amendments require the industry to produce greater quantities of oxygenated gasoline, and lower sulfur diesel and reformulated gasoline. Biochemical technology may play an important role in responding to these demands on the petroleum industry.

Since oil is of biological origin, some biochemical reactions started at the beginning of its formation are still continuing in reservoirs on a geological time scale. Although these rates are very

\footnotetext{
Author to whom all correspondence and reprint requests should be addressed.
} 
slow, many reactions can proceed readily under optimal conditions. This article will address some of the reactions that may be useful for processing heavy oils and refinery residuum.

\section{METHODS}

\section{Biochemical Treatment of Oils}

Detailed descriptions of biocatalysts and their treatment of crude oils have been published elsewhere and will be briefly summarized here $(1,2)$. The treatment was carried out in a glass reactor fitted with stirrer, condenser, heater, and temperature controller. The reaction was started by mixing the oil samples and biocatalysts together. As the reaction progressed, a metastable emulsion formed, which was maintained by constant stirring. After culturing at $55^{\circ} \mathrm{C}$ for periods of $3-4 \mathrm{~d}$, the product mixtures were extracted with methylene chloride with better than $94 \%$ oil recovery.

Control runs without inoculation of microbes have been described previously (2). The observable effect in control runs is very small and does not affect the experimental results. For example, in a typical emulsification experiment using BNL-4-23 and Monterey A837, the control effect expressed in Klett units (3) is $\sim 10 \%$, as shown in Table 1 . In this experiment, two controls were used, one for microorganisms (M.O.) only without oil and the other ("Control Oil") oil and medium only. The latter indicates the possible effect of the "indigenous" rather then introduced microbes under the experimental condition used. 


\section{Carbon, Hydrogen, Nitrogen and Sulfur (CHNS) Analysis}

Carbon, hydrogen, nitrogen, and sulfur content were analyzed by Huffman Analytic Company, Golden, Colorado.

\section{Gas Chromatography Nitrogen (NPD) Selective Analysis}

A Varian model 3400 gas chromatograph equipped with a thermionic detector was used to analyze the organonitrogen compounds in crude oils. Analyses were performed on an SE-30 capillary column ( $30 \mathrm{~m}$ in length, $0.32 \mathrm{~mm}$ in diameter). The temperature program was as follows: $50^{\circ} \mathrm{C}$ for $1 \mathrm{~min}$, a ramp of $8^{\circ} \mathrm{C} / \mathrm{min}$ to $320^{\circ} \mathrm{C}$ for 20 minutes, and an He flowrate of $2 \mathrm{~mL} / \mathrm{min}$. The instrument was calibrated by using a standard Varian analytical instrument P/N 82-005048-04. Gas Chromatograph Mass Spectrometry (GC-MS) and Sulfur Specific (FPD) Analysis

A Perkin-Elmer model 8700 gas chromatograph, equipped with a splitter, was used for simultaneous mass spectrometric and photometric analysis. In conjunction with the EPANIH library for identification of hydrocarbons, FPD analyses were calibrated against standard organosulfur compounds $(1,2)$.

\section{Element Analysis}

Oil samples were digested with concentrated nitric acid and then analyzed by inductively coupled plasma mass spectrometry (ICPMS, Fisons Instrument model PQ2+) using Indium as an internal standard. A factory-specified procedure was used to calibrate the instrument (Fisons Instruments, Beverly, MA). For quantitative analyses, the instruments were calibrated with known standards (ICPMS-SET SPEX Company, Edison, NJ). 


\section{RESULTS AND DISCUSSION}

Methodology for the biochemical processing of crudes as used in the present work has been described in detail elsewhere $(1,2,3)$. Briefly, biocatalysts, i.e, microorganisms and the reaction medium, are allowed to interact with oil in a two-phase oil-aqueous system. Efficient agitation at the elevated temperature allows for the formation of fine dispersion of oil particles in the aqueous phase. Biochemical reactions occur at the oil-water interface, and are initiated at the heteroatom sites (3), which leads to a form of biodepolymerization within the asphaltene fraction of the heavy crudes. Emulsifying agents, which are concurrently formed, enhance the mixing of the reactants and, therefore, accelerate the reaction rates. Optimization of such processing parameters contributes to the development of the biochemical oil treatment methodology.

Results shown in Table 2 indicate that a decrease of up to $45 \%$ of total nitrogen and $50 \%$ of total sulfur content occurs when all the matter has been accounted for by mass balance calculation. The mass balance calculation is based on total oil recovery and elemental analysis (CHNS), which shows a significant decrease in the sulfur content (1-3). Further, as shown in Fig. 1, treated v. untreated OSC oil shows a reduction in medium to high sulfur peaks ranging from benzothiophene to dibenzothiophene (20 to $35 \mathrm{~min}$ retention times, respectively).

Corresponding analysis of hydrocarbon alkane compounds by GC using a mass specific detector is shown in Fig. 2. The untreated Midway Sunset Oil (MWS) consists of polar and heavy fractions that cannot be resolved into typical alkane chromatographic profile. The treated sample was separated into distinct light alkane peaks at 20 to $40 \mathrm{~min}$. retention times. The results indicate 
that biochemical treatment converted heavy oil into lighter hydrocarbons. Although there is a significant decrease in total nitrogen content ( $>25 \%)$, the resolution of major peaks needs further refining. The improvement in the analytical procedure is in progress, and current results indicate that the biochemical conversion of organonitrogen compounds leads to the formation of complex mixtures. The organonitrogen and organosulfur compounds present in the large molecular weight fraction of crude oils are converted to lighter fractions with a simultaneous decrease in the total heteroatom contents. The nature of the end products is currently being investigated.

Biochemical reactions also reduce the metal content of fossil fuels. In addition to our previous observations for vanadium and nickel (1-3), the removal of other trace metals (e.g., $\mathrm{Pb}$, $\mathrm{Hg}, \mathrm{Zr}, \mathrm{Ag}, \mathrm{Mo}$, and $\mathrm{Sr}$ ) is also significant. Further, the removal of toxic elements (e.g., Se and As) is quantitative. The results are given in Table 3.

\section{CONCLUSION}

Biochemical reactions leading to upgraded oils from mixtures as complex as crude oils are intricate and proceed via multiple inter- and intramolecular reactions involving depolymerization, desulfurization, denitrification, and demetalation pathways. Therefore, such biochemical reactions can be used to monitor the development of pretreatment processes applicable to crude oils in pipelines and storage tanks to save processing time and space. They may also be used for processing of downstream heavy fuels, residuum, and wastes in refineries.

Current studies at Brookhaven National Laboratory are focusing on scaled-up processing and extensive cost-efficiency analyses of processes based on the chemical changes in the 
heteroatom contents and the distribution of hydrocarbons. Preliminary results indicate that the emerging biochemical technology is promising and technically achievable (4-6).

Heavy oils, residuum, and oil wastes represent a substantial resource if a low-cost technology for their processing could be developed. In terms of reserves, $50-70 \%$ of original oil is still in place and is available. However, it is heavy and requires extensive secondary and tertiary recovery technology. Similarly, wastes from oil processing amount to 400 million gallons annually. Over the past few years at Brookhaven National Laboratory (BNL), we have been investigating biochemical processes for the treatment of heavy crude oils and heavy fractions of crude oils. Particular attention has been given to the interactions between extremophilic microorganisms (i.e., high temperature, pressure, salinity) and selected heavy oils. Significant biochemical conversions occur, leading to lighter oils. Recent advances in these studies have been presented and their significance discussed.

\section{ACKNOWLEDGEMENTS}

This work is performed under the auspices of the US DOE Contract No. DE-AC02$76 \mathrm{CH} 00016$.

\section{REFERENCES}

1. Premuzic, E.T. and Lin, M.S. (1990), in Microbial Enhancement of Oil Recovery, vol. 31, Donaldson, E., ed., Elsevier, New York, pp. 277-296, 1990.

2. Premuzic, E.T., Lin, M.S., Jin, J.-Z., Manowitz, B., and Racaniello, L. (1993), Biochemical Alteration of Crude Oils in Microbial Enhanced Oil Recovery, Biohydrometallurgical Technologies, Torma, A.E., Apel, M.L., and Brierley, C.L., eds., The Minerals, Metals \& Materials Society, pp. 401-413.

3. Rosenberg, E., Zuckerberg, A., Rubinowitz, C., and Gutnick, D.L. (1979), Appl. Environ. Microbial. 37(3), 402-408. 
4. Premuzic, E.T., Lin, M.S., and Manowitz, B. (1994), Fuel Processing Technol. 40, 227239.

5. Premuzic, E.T., Lin, M.S., and Lian, H. (1995), Bioconversion of Heavy Crude Oils: A Basis for New Technology, Presented at the XIth Caribbean Conference of Chemistry \& Chemical Engineering, St. Augustine, Trinidad \& Tobago, West Indies, March 6-10, 1995.

6. Dounias, G., Economic Feasibility of Biochemically Upgrading Heavy Crudes, in preparation.

\section{FIGURE CAPTIONS}

Fig. 1. Gas chromatograph sulfur selective (FPD) analysis.

Fig. 2. Gas chromatograph-mass spectrometer analysis for alkanes (A) MWS crude oil treated with BNL 4-23. (B) Untreated MWS heavy crude oil. 
Table 1

Extent of Emulsification

\begin{tabular}{lcc} 
M.O. & \%Oil & $\begin{array}{c}\text { Emulsion, } \\
\text { (Klett units) }\end{array}$ \\
\hline BNL-4-23 & 0.5 & 2000 \\
BNL-4-23 Control & 0 & 95 \\
A837 Control Oil & 0.5 & 255 \\
\hline
\end{tabular}


Table 2

Biochemical Treatment of MWS and

$\mathrm{OSC}$ at $55^{\circ} \mathrm{C}$ for $3-4 \mathrm{~d}$

\begin{tabular}{|c|c|c|c|c|c|c|c|}
\hline \multirow[t]{2}{*}{ Biotreatment } & \multirow[t]{2}{*}{$\begin{array}{c}\% \text { Oil } \\
\text { Recovered }\end{array}$} & \multicolumn{4}{|c|}{ Elemental Analysis \% } & \multicolumn{2}{|c|}{$\begin{array}{c}\% \\
\text { Heteroelement } \\
\text { Removal }\end{array}$} \\
\hline & & $\mathrm{C}$ & $\mathrm{H}$ & $\mathrm{N}$ & S & $\mathbf{N}$ & $\mathbf{S}$ \\
\hline control MWS untreated & & 86.45 & 10.99 & 0.79 & 1.00 & & \\
\hline MWS treated with BNL 4-23 & 101 & 86.02 & 11.67 & 0.64 & 0.50 & 20 & 50 \\
\hline MWS treated with BNL 4-22 & 94 & 86.00 & 11.21 & 0.59 & 0.80 & 25 & 20 \\
\hline control untreated OSC & & 82.31 & 11.17 & 0.66 & 4.40 & & \\
\hline OSC treated with BNL 4-22 & 100 & 83.87 & 11.75 & 0.53 & 4.20 & 20 & 5 \\
\hline OSC treated with BNL 4-23 & 99 & 84.45 & 12.39 & 0.36 & 2.40 & 45 & 45 \\
\hline
\end{tabular}


Table 3

Metal Removal by Biotreatment

\begin{tabular}{|c|c|c|c|c|c|c|}
\hline \multirow{2}{*}{$\frac{\text { Element }}{\text { Vanadium }}$} & \multirow{2}{*}{$\begin{array}{c}\text { MWS } \\
\text { untreated } \\
\mu \mathrm{g} / \mathrm{g}^{2} \\
23.50\end{array}$} & $\begin{array}{c}\text { MWS } \\
\text { treated } \\
\text { BNL 4-23 } \\
\mu g / g^{*} \%\end{array}$ & $\begin{array}{c}\text { MWS } \\
\text { treated } \\
\text { BNL 4-22 } \\
\mu \mathrm{g} / \mathrm{g}^{\mathrm{a}} \%\end{array}$ & \multirow{2}{*}{$\begin{array}{c}\text { OSC } \\
\text { untreated } \\
\mu \mathrm{g} / \mathrm{g}^{\mathrm{a}} \\
202.00\end{array}$} & \multicolumn{2}{|c|}{$\begin{array}{l}\text { OSC } \\
\text { treated } \\
\text { BNL 4-23 } \\
\mu \mathrm{g} / \mathrm{g}^{2} \%^{\mathrm{b}}\end{array}$} \\
\hline & & 15.20 & $18.80 \quad 20$ & & 171.0 & 16 \\
\hline Nickel & 62.80 & 46.80 & $51.80 \quad 18$ & 79.2 & 63.8 & 20 \\
\hline Lead & 2.87 & 2.05 & 0.1495 & 8.03 & 7.7 & 5 \\
\hline Mercury & 0.58 & $0.00 \quad 100$ & $0.02 \quad 96$ & 0.04 & 0.0 & 100 \\
\hline Zirconium & 1.08 & 0.57 & 1.23 & 1.39 & 0.86 & 38 \\
\hline Silver & 0.67 & $0.00 \quad 100$ & $0.00 \quad 100$ & 0.07 & 0.09 & 0 \\
\hline Molybdenum & 0.70 & 0.12 & 0.19 & 1.51 & 0.8 & 46 \\
\hline Strontium & 0.31 & 0.09 & 0.58 & 0.86 & 0.1 & 87 \\
\hline Selenium & 0.04 & 100 & $0.0 \quad 100$ & 0.19 & 0.0 & 100 \\
\hline Arsenic & 0.51 & 0.009 & $0.06 \quad 88$ & 0.28 & 0.0 & 100 \\
\hline
\end{tabular}

Metal content in oil samples as $\mu \mathrm{g}$ of metal/g of oil.

Percentage metal removal by biotreatment in comparison to corresponding untreated samples. 


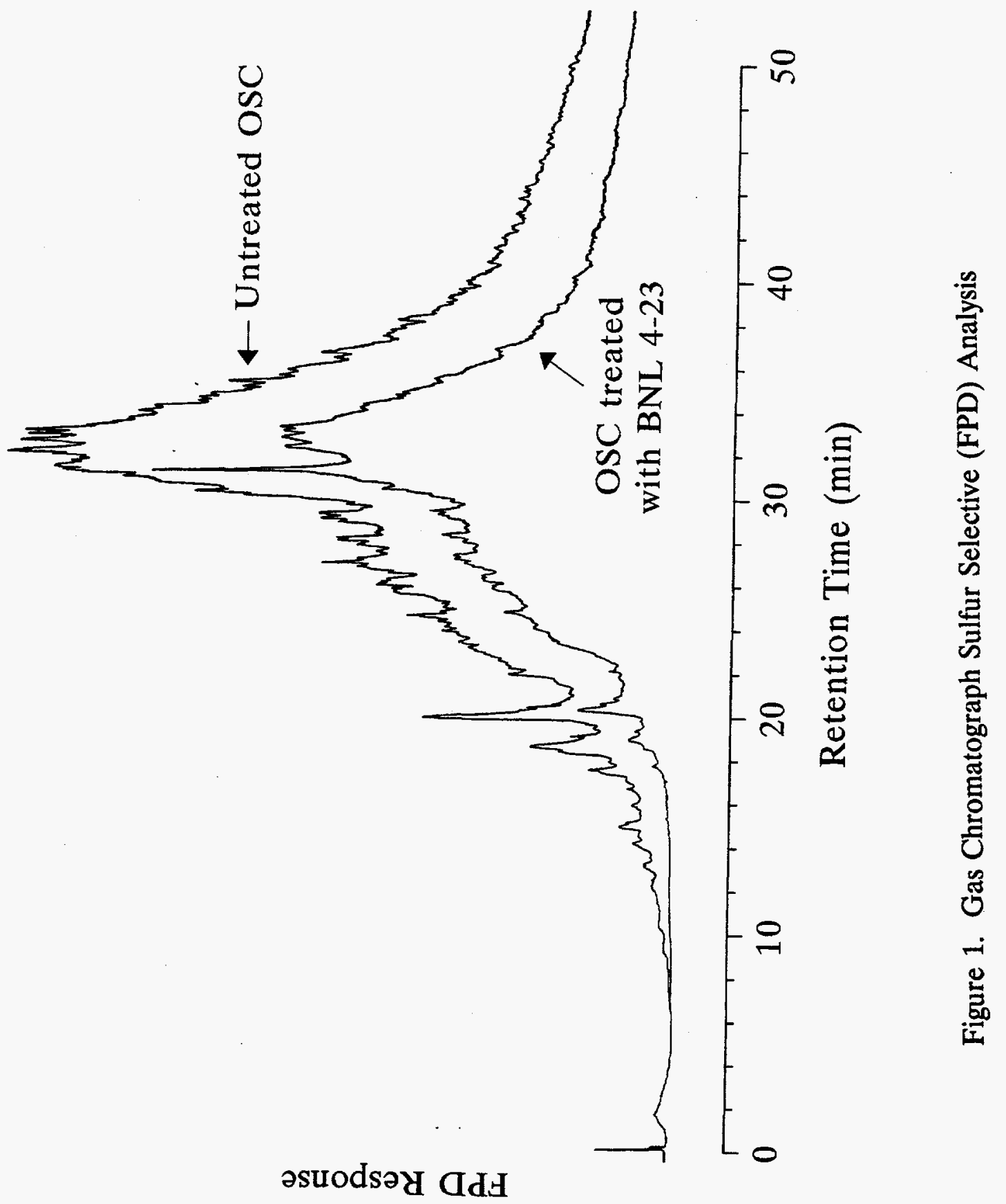




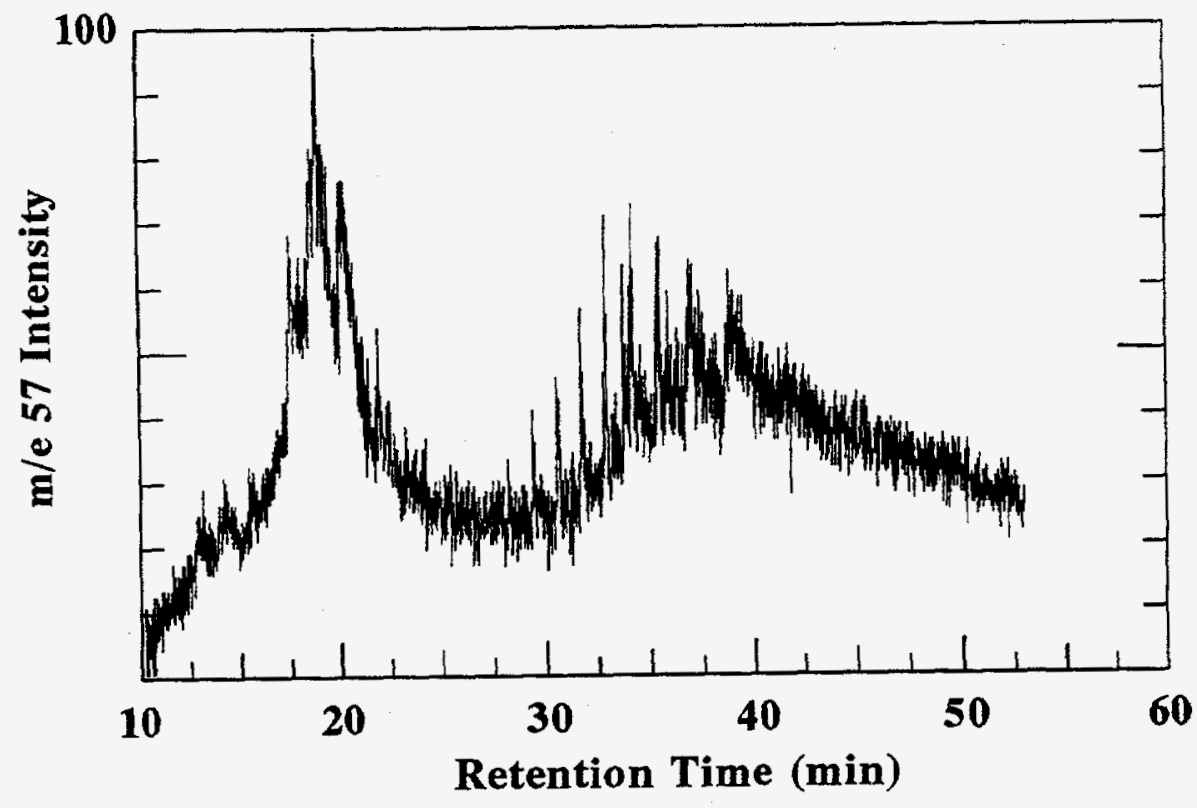

(a)

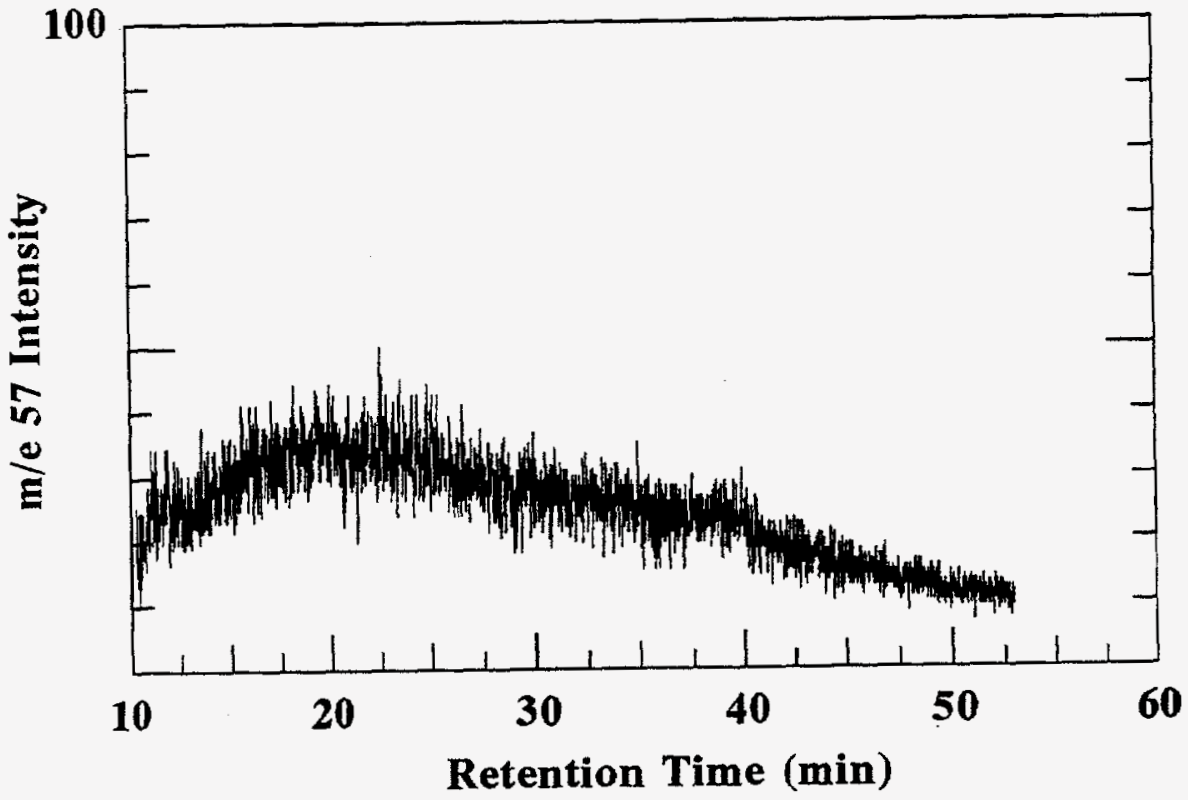

(b)

Figure 2. Gas Chromatograph-Mass Spectrometer analysis for alkanes (a) MWS crude oil treated with BNL 4-23. (b) Untreated MWS heavy crude oil. 